\title{
Bronchodilator premedication does not decrease respiratory adverse events in pediatric general anesthesia
}

\author{
[Une prémédication bronchodilatatrice ne réduit pas les événements respiratoires \\ indésirables en anesthésie générale pédiatrique]
}

Tom Elwood MD, ${ }^{*}$ William Morris MD, $†$ Lynn D. Martin MD, ${ }^{*}$ Mary-Kay Nespeca Rn, ${ }^{*}$ David A. Wilson PhD, $\ddagger$ Lee A. Fleisher MD, $\ddagger$ James L. Robotham MD FRCA, $\$$ David G. Nichols MD $\ddagger$

\begin{abstract}
Purpose: Upper respiratory infections (URI) presage perioperative respiratory complications, but thresholds to cancel surgery vary widely. We hypothesized that autonomically-mediated complications seen during emergence from anesthesia would be predicted by capnometry and reduced with preoperative bronchodilator administration.
\end{abstract}

Methods: Afebrile outpatient tertiary-care children (age two months to $18 \mathrm{yr}, n=109$ ) without lung disease or findings, having non-cavitary, non-airway surgery for under three hours, were randomized to bronchodilator premedication vs placebo and had preoperative capnometry. After halothane via mask, laryngeal mask airway, or endotracheal tube, and regional anesthesia as appropriate, patients recovered breathing room air while cough, wheeze, stridor, laryngospasm, and cumulative desaturations were recorded for 15 min.

Results: In this specific population, there was no association between adverse events and either URI within six weeks $(n=76)$ or URI within seven days $(n=21)$. Neither albuterol nor ipratropium premedication decreased adverse events. Endotracheal intubation was associated with increased emergence desaturations and placebo nebulized saline increased emergence coughing. Neither anesthesiologists nor preoperative capnometry predicted adverse events.

Conclusions: Adverse events were neither predicted nor prevented. In afebrile outpatient ASA I and II children with no lung disease or findings, having non-cavitary, non-airway surgery for under three hours, there was no association between either recent URI or active URI and desaturation, wheeze, cough, stridor, or laryngospasm causing desaturation (all $P>0.05$ ). In this highly selected population of afebrile patients, the results suggest that anesthesiologists may proceed with surgery using specific criteria in the presence of a URI.

Objectif : Les infections des voies respiratoires supérieures (IRS) présagent des complications respiratoires périopératoires, mais les valeurs seuils qui pourraient faire annuler l'opération chirurgicale varient beaucoup. Notre hypothèse était que les complications d'origine autonome pendant le réveil post-anesthésique, pourraient être prédites par la capnométrie et réduites par l'administration préopératoire de bronchodilatateur.

Méthode : Des enfants afébriles admis à l'unité externe de soins tertiaires, (deux mois à 18 ans, $n=109$ ), sans infection pulmonaire connue ou constatée, devant subir une opération de moins de trois heures ne touchant ni une cavité ni les voies aériennes, ont été répartis de façon aléatoire pour recevoir une prémédication bronchodilatatrice ou un placebo, et ont été soumis à une capnométrie préopératoire. Après l'administration d'halothane par masque, la mise en place d'un masque laryngé, ou d'un tube endotrachéal, et l'anesthésie régionale quand c'était indiqué, les patients ont respiré spontanément l'air ambiant. Toux, respiration sifflante, stridor, laryngospasme et désaturation cumulative ont été enregistrés pendant 15 min.

Résultats : Dans cette population spécifique, aucun lien n'a été noté entre les événements indésirables et, soit une IRS dans les six dernières semaines $(n=76)$ ou les sept derniers jours $(n=21)$. La prémédication avec albutérol ou ipratropium n'a pas réduit les événements indésirables. L'intubation endotrachéale a été associée à une désaturation accrue au réveil et la solution saline en aérosol a augmenté la

From the Departments of Anesthesiology, ${ }^{*}$ Children's Hospital and Regional Medical Center, Seattle, Washington; Emergency Medicine, $\dagger$ University of Washington School of Medicine, Washington; Anesthesiology, $\ddagger$ University of Rochester Medical Center, Rochester, New York; and Anesthesiology and Critical Care Medicine, $\$$ John Hopkins Hospital, Baltimore, Maryland, USA.

Address correspondence to: Dr. Tom Elwood, Department of Anesthesiology, Children's Hospital and Regional Medical Center, 4800 Sand Point Way NE, Seattle, Washington 98105, USA. Phone: 206-987-2123; Fax: 206-987-3935; E-mail: tomelwood@hotmail.com This study was carried out at Johns Hopkins Hospital, Baltimore, MD and Children's Hospital and Regional Medical Centre, Seattle, WA, USA.

Accepted for publication July 12, 2002.

Revision accepted December 13, 2002. 
toux au réveil. Ni les anesthésiologistes, ni la capnométrie préopératoire n'ont pu prédire les événements indésirables.

Conclusion : Les événements indésirables n'ont été ni prédits, ni prévenus. Chez les enfants sélectionnés, aucun lien entre une IRS récente ou active et la désaturation, la respiration sifflante ou le laryngospasme causant la désaturation (tous les $P>0,05$ ) n'a été établi. Les résultats indiquent que les anesthésiologistes doivent suivre des critères spécifiques en cas d'IRS.

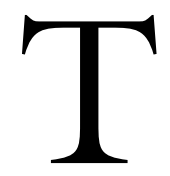

HE association between a recent upper respiratory tract infection (URI) and respiratory adverse events, such as bronchospasm, laryngospasm, and hemoglobin desaturation during general anesthesia, has been documented both retrospectively ${ }^{1-4}$ and prospectively. ${ }^{5-8}$ This is a common challenge in pediatric anesthesia, since previous studies have shown a $30-40 \%$ prevalence of recent URI in an unselected population presenting for elective surgery. ${ }^{6,9}$ Elective surgery may be cancelled because of recent URI, although individual practice varies widely. ${ }^{10}$ The circumvention of complications that cancellation achieves may not justify the inconvenience of postponing a procedure, ${ }^{11}$ especially since another URI may develop while awaiting rescheduled surgery - children have an average of six URI per year. ${ }^{12}$ While the association between recent URI and respiratory-related adverse events is well documented, the implication for a given child with a recent URI is not clear.

An upper respiratory tract infection affects both upper and lower airways. Studies in adults have documented increased airway resistance persisting for six to eight weeks after URI, ${ }^{13,14}$ long beyond clinical resolution of acute illness, reversible with bronchodilator administration..$^{13}$ Furthermore, the airway resistance increase seen immediately after intubation in adults can be attenuated by bronchodilator administration. ${ }^{15}$ Though adverse events during emergence from anesthesia are not common, recent URI does increase their incidence - specifically bronchospasm ${ }^{1,6,7}$ and laryngospasm. ${ }^{8,16}$ The role of the autonomic nervous system in laryngospasm and bronchospasm suggested a role for bronchodilator administration. We hypothesized that desaturation during emergence from anesthesia would be decreased with the administration of preoperative bronchodilator.

In searching for a preoperative predictive test, we recognized that young children are unable to cooperate with conventional tests of respiratory mechanics. The correlation between expired carbon dioxide $\left(\mathrm{CO}_{2}\right)$ waveforms and simple spirometry in adults ${ }^{17}$ suggested capnography could provide a preoperative marker of altered airway resistance seen after URI in children. In support of this, the nitrogen washout curve (analogous to the expired capnograph) was significantly changed during URI in teenagers. ${ }^{18}$ We hypothesized perioperative respiratory adverse events from altered airway resistance might be predicted from preoperative capnography. We compared this to the available alternative - prediction of adverse events by the anesthesiologist.

We undertook this study in two phases, to assess the effect of two bronchodilators on emergence desaturations in a block-randomized, age-stratified, double-blind controlled trial of bronchodilator premedication in children.

\section{Methods}

An URI was defined as two or more of the following symptoms (sore throat, sneeze, rhinorrhea, congestion, malaise, cough, fever, hoarseness), with certain pairs requiring a third symptom, as outlined previously. ${ }^{19}$ An active URI specified peak symptoms, as recalled by parents, occurred within seven preoperative days. True laryngospasm is a rare event. In an effort to capture all events related to laryngospasm, stridor-laryngospasm was defined as high-pitched monophonic inspiratory sounds accompanied by difficulty with ventilation, while laryngospasm specified desaturation below $93 \%$ in addition.

With approval from respective Institutional Review Boards, 135 children were enrolled. Patients were enrolled without knowledge of their history of recent or active URI. Inclusion criteria were: scheduled outpatient elective surgical procedures less than three hours, age two months to $18 \mathrm{yr}$, ASA physical status I or II, and planned mask induction and halothane maintenance. Exclusion criteria were: diagnosis of asthma or other chronic lung disease given by a physician, history of prematurity ( $<36$ weeks gestation) in infants less than 12 months of age, rhonchi or coarse rales evident on preoperative lung auscultation, fever $\left(>38^{\circ} \mathrm{C}\right.$ axillary, ) or deviations from study protocol. Patients having surgery of the airway (i.e., potential surgical bleeding in the pharynx), cranium, chest, or upper abdomen were excluded since surgical factors (e.g., blood in the airway, altered mental status, chest wall splinting) could confound.

\section{Phase I (ipratropium, Baltimore)}

After obtaining written consent and assent where appropriate, a preoperative capnograph tracing (Hewlett-Packard HP 47210A capnometer, Palo Alto, CA, USA, calibrated daily), recorded using an ana- 
logue to digital conversion at $40 \mathrm{Hertz}$, was obtained by placing an appropriately sized tight-fitting facemask onto the patient with an in-line infrared capnograph sensor attached (but no anesthetic circuit), recording quiet breathing for up to three minutes as tolerated by the patient. Patients breathed naturally without coaching. The facemask-sensor volume was $40 \mathrm{~mL}$ for patients less than two years, and $78 \mathrm{~mL}$ for older children. The capnograph sensor cell was autoclaved after each patient use.

Three groups were studied: premedication with ipratropium, normal saline, or non-intervention (no inhaled premedication). A computer-generated random sequence assigned patients to groups in blocks of nine, and the randomization code remained unbroken until completion of each phase of the study. Randomization was stratified according to intention to intubate or not, and stratified according to age (0-1, 1-2, 2-5, and > 5 yr-old).

Patients then received the study medication according to a sealed envelope. Group 1 received ipratropium ( $500 \mu \mathrm{g}$ or $250 \mu \mathrm{g}$ if $<2$ yr-old) in $2.5 \mathrm{~mL}$ normal saline, Group 2 received $2.5 \mathrm{~mL}$ normal saline, and Group 3 received no inhaled premedication. The medication was prepared by a non-investigator, placed in a nebulizer with $8 \mathrm{~L} \cdot \mathrm{min}^{-1}$ of non-humidified oxygen at room temperature, and administered over six to eight minutes.

A second capnograph tracing was obtained at least 15 min after administration of the nebulized premedication, to allow time for onset of drug effect. ${ }^{20}$

Anesthetic care for each patient was managed by the attending anesthesiologist and resident assigned to the case, who were blinded to randomized pre-treatment. Midazolam oral premedication $\left(0.5 \mathrm{mg} \cdot \mathrm{kg}^{-1}\right)$ was given, if indicated, followed by halothane inhalational induction in $\mathrm{N}_{2} \mathrm{O}$ using non-humidified anesthetic circuits. Rectal acetaminophen, regional or local anesthesia provided analgesia while atropine and opioid administration were avoided in all patients. Vecuronium was the relaxant used when intubation was performed, to avoid histamine release or effects at the muscarinic receptor. ${ }^{21}$ Anesthesia was maintained with halothane and nitrous oxide, titrated by the anesthesiologist managing the case.

Patients were extubated either awake or deeply anesthetized, at the anesthesiologist's discretion. Patients recovered in the lateral position, breathing room air during transport and in the postanesthesia care unit (PACU). Supplemental oxygen was administered only while $\mathrm{SpO}_{2}$ remained below $93 \%$.

After pre-anesthesia assessment, baseline oxygen saturation and heart rate were obtained, and the attending anesthesiologist made an informed assessment of the risk of perioperative desaturation, laryngospasm, and bronchospasm. End-points were recorded during induction for five minutes after face mask application, and for 15 min during emergence after facemask removal. A single designated pulse oximeter (Nellcor N100, Pleasanton, CA, USA), set in rapid-averaging mode, was used for all patients, with a fresh sensor for each patient. An observer blinded to study medication and URI status monitored beat-to-beat oxygen saturations, and using two stopwatches recorded the cumulative duration of desaturation below $95 \%$ and below $85 \%$, auscultated for wheezing, and counted coughs (each expulsive effort). The ordinal scale for stridor and laryngospasm was: $1=$ stridor (inspiratory high-pitched monophonic) only; $2=1$ plus desaturation $<93 \% ; 3=2$ plus continuous positive airway pressure (CPAP) required; $4=$ 3 plus duration $>30 \mathrm{sec}$ despite CPAP; and $5=$ administration of muscle relaxant for failure of previous measures. End-tidal halothane concentration was recorded when the surgical dressing was finished, and immediately before extubation. When available, a random second blinded observer recorded all endpoints in order to assess inter-rater reliability.

We recorded procedure, duration of surgery, level of training of the person managing the airway, type of airway management (mask, laryngeal mask, or endotracheal tube), use of regional anesthesia, duration of PACU stay, unplanned admission to hospital, and deviations from protocol.

Postoperatively, parents graded preoperative URI symptoms $^{19}$ as mild, moderate or severe; specifically sore throat, hoarseness, 'stuffiness', runny nose, cough, sneezing, fever and malaise. Two other symptoms shown to improve in children recovering from URI (poor appetite and altered sleep) were graded. ${ }^{22}$

\section{Phase II (albuterol, Seattle)}

Capnometry in phase I was poorly tolerated, producing substantial artifact. We performed capnography in phase II with nasal prongs using a side-stream aspirating infrared spectrometer gas analyzer.

Nebulized saline as been shown to increase airway resistance in some studies. ${ }^{23,24}$ Phase I results showed nebulized saline significantly increased emergence coughing compared to the non-intervention group (Table II). Since coughing could affect other endpoints, the nebulized saline was abandoned; the nonintervention group became the only comparison group.

Albuterol $2.5 \mathrm{mg}(0.5 \mathrm{~mL})$ added to $2.5 \mathrm{~mL}$ saline was nebulized as in phase I. Control subjects received $8 \mathrm{~L} \cdot \mathrm{min}^{-1}$ oxygen through an empty identical nebuliz- 
TABLE I Patient characteristics

\begin{tabular}{|c|c|c|c|c|c|c|c|}
\hline & $\begin{array}{l}\text { Phase } I \\
n=58 \\
\text { Ipratropium } \\
n=18\end{array}$ & $\begin{array}{l}\text { Placebo } \\
n=23\end{array}$ & $\begin{array}{l}\text { Non-intervention } \\
n=17\end{array}$ & P-value & $\begin{array}{l}\text { Phase II } \\
n=51 \\
\text { Albuterol } \\
n=26\end{array}$ & $\begin{array}{l}\text { No-intervention } \\
n=25\end{array}$ & P-value \\
\hline Age (months) & $41(15,101)$ & $38(17,71)$ & $40(14,72)$ & 0.98 & $21(12,53)$ & $30(11,44)$ & $\begin{array}{l}0.98 \\
0.39 \text { all gp }\end{array}$ \\
\hline Weight (kg) & $14(9,28)$ & $16(13,20)$ & $13(11,21)$ & 0.78 & $12(9,18)$ & $13(10,15)$ & 0.96 \\
\hline Males & $13(72 \%)$ & $17(74 \%)$ & $16(94 \%)$ & 0.20 & $17(68 \%)$ & $15(60 \%)$ & 0.77 \\
\hline Caucasian \% & $15(83 \%)$ & $16(70 \%)$ & $16(94 \%)$ & 0.33 & $18(72 \%)$ & $17(68 \%)$ & 1 \\
\hline Daycare attendance & $14(78 \%)$ & $8(40 \%)$ & $8(50 \%)$ & 0.056 & $12(48 \%)$ & $9(36 \%)$ & 0.57 \\
\hline Smoke exposure & $5(31 \%)$ & $11(50 \%)$ & $7(41 \%)$ & 0.51 & $7(28 \%)$ & $7(28 \%)$ & 1 \\
\hline Midazolam given & $7(39 \%)$ & $14(61 \%)$ & $9(56 \%)$ & 0.35 & $15(79 \%)$ & $19(86 \%)$ & $\begin{array}{l}0.68 \\
0.038 \text { all gp }\end{array}$ \\
\hline $\begin{array}{l}\text { Time from broncho-dilator } \\
\text { to OR ( } \mathrm{min})\end{array}$ & $21(16,79)$ & $35(20,44)$ & NA & 0.52 & $29(14,45)$ & NA & $\begin{array}{l}0.52 \\
\text { all gp }\end{array}$ \\
\hline Baseline saturation & $100(100,100)$ & $100(100,100)$ & ) $100(100,100)$ & 0.74 & $100(100,100)$ & $100(100,100)$ & 0.97 \\
\hline Intubation & $3(17 \%)$ & $7(30 \%)$ & $1(6 \%)$ & 0.36 & $10(40 \%)$ & $7(28 \%)$ & $\begin{array}{l}0.55 \\
0.058 \text { all gp }\end{array}$ \\
\hline LMA use & $2(11 \%)$ & $1(4 \%)$ & $2(12 \%)$ & 0.36 & $4(16 \%)$ & $11(44 \%)$ & 0.10 \\
\hline Resident-managed & $16(94 \%)$ & $22(96 \%)$ & $16(100 \%)$ & 0.68 & $11(42 \%)$ & $10(42 \%)$ & $\begin{array}{l}1, \\
0.0002 \text { all gp }\end{array}$ \\
\hline $\begin{array}{l}\text { Resident pediatric } \\
\text { experience (weeks) }\end{array}$ & $7(4,8)$ & $9(4,16)$ & $6(4,12)$ & 0.41 & $8(2,11)$ & $3(1,8)$ & 0.12 \\
\hline OR duration (min) & $55(30,93)$ & $62(32,110)$ & $52(23,74)$ & 0.38 & $42(15,77)$ & $41(29,84)$ & 0.56 \\
\hline Deep extubations & 0 & 0 & 0 & 1 & $13(59 \%)$ & $13(59 \%)$ & 1 \\
\hline Active URI & $2(11 \%)$ & $5(22 \%)$ & $1(6 \%)$ & 0.4 & $4(15 \%)$ & $2(8 \%)$ & 0.67 \\
\hline Recent URI & $12(67 \%)$ & $17(74 \%)$ & $11(65 \%)$ & 0.79 & $18(69 \%)$ & $18(72 \%)$ & 1 \\
\hline Recent URI (wk) & $2(1,5)$ & $3(0.6,4)$ & $4(1,5)$ & 0.66 & $2(0.5,3)$ & $2(1.8,4)$ & 0.40 \\
\hline PACU time (min) & $103(74,136)$ & $105(90,115)$ & $90(70,120)$ & 0.57 & $30(20,53)$ & $30(20,48)$ & 1 \\
\hline
\end{tabular}

Resident-managed $=$ percentage of cases with airway managed by residents; resident week experience $=$ residents' median weeks pediatric experience for each case; OR duration = time from induction to completion of surgical dressing; active URI = less than one week since peak symptoms; recent URI = between one and six weeks since peak symptoms; LMA = laryngeal mask airway; PACU time = minutes spent in acute phase post-anesthesia care unit; all gp = comparison across all groups in the table.

er apparatus. In keeping with the local standard of care, the induction agent became sevoflurane, and was switched to halothane before intubation.

Capnometry was performed before and at minimum five minutes after study medication to allow time for onset of albuterol, ${ }^{25}$ using a Datex Capnomac Ultima Capnometer (Datex-Ohmeda Division, Helsinki, Finland, calibrated daily, recorded with analogue to digital conversion at $40 \mathrm{Hertz}$ ), and an appropriately sized nasal cannula having the shortest available aspirating tube to minimize signal distortion (Salter Labs, Arvin, CA, USA \#4706 and 4701F, $58 \mathrm{~cm}$ ).

\section{Analysis}

Continuous variables that failed to show a normal distribution with the Shapiro-Wilk W test were compared using the Wilcoxon rank sum test (WRS) and proportions were compared using Fisher's exact test (FE) or Pearson chi-square where appropriate.
Two potential outcome predictors were derived from each capnograph to describe its shape, based on a previous adult study. ${ }^{17}$ The second derivative with respect to time (the rate of slope change) was calculated, and peak expiratory values of the second derivative were calculated. Each breath was integrated from $\mathrm{CO}_{2}$ $>5 \mathrm{mmHg}$ to end-tidal and the area was expressed as a proportion of the total area in a rectangle of the same width having a height of $\mathrm{ETCO}_{2}$. Breaths were rejected if they were $<0.8 \mathrm{sec},>3 \mathrm{sec}, \mathrm{ETCO}_{2}<22.5 \mathrm{mmHg}$, or if severely deformed by artifact.

Sample size (based on a power $>80 \%$ and alpha $=$ 0.05 ) was estimated from a previous study of intraoperative desaturations in children with and without URI $(40 \% \text { vs } 15.6 \%)^{7}$ as 42 patients per group. Significance was taken at the 0.05 level.

Data are presented as mean (SD) or median (25th percentile, 75 th percentile) as appropriate. Analysis of inter-rater reliability can give falsely high reliability val- 
TABLE II Outcomes in all patients

\begin{tabular}{|c|c|c|c|c|c|c|c|}
\hline & $\begin{array}{l}\text { Phase I } \\
n=58 \\
\text { Ipratropium } \\
n=18\end{array}$ & $\begin{array}{l}\text { Placebo } \\
n=23\end{array}$ & $\begin{array}{l}\text { Non-intervention } \\
n=17\end{array}$ & P value & $\begin{array}{l}\text { Phase II } \\
n=51 \\
\text { Albuterol } \\
n=26\end{array}$ & $\begin{array}{l}\text { No-intervention } \\
n=25\end{array}$ & P value \\
\hline Stridor-laryngospasm & $1(6 \%)$ & $2(9 \%)$ & $0(0 \%)$ & 0.47 & $4(15 \%)$ & $4(16 \%)$ & 1 \\
\hline Laryngospasm & $1(6 \%)$ & $1(4 \%)$ & $0(0 \%)$ & 0.64 & $3(12 \%)$ & $3(12 \%)$ & 1 \\
\hline Desaturation < $95 \%(\mathrm{sec})$ & $0(0,32)$ & $0.6(0,74)$ & $0(0,7)$ & 0.55 & $0(0,96)$ & $0(0,94)$ & 0.80 \\
\hline Desaturation < 85\% (sec) & $0(0,0)$ & $0(0,0)$ & $0(0,0)$ & 0.49 & $0(0,0)$ & $0(0,0)$ & 0.47 \\
\hline Wheeze & 0 & 0 & 0 & 0 & $2(8 \%)$ & $3(12 \%)$ & 0.67 \\
\hline Cough & $0(0,6)$ & $2(0,11)^{*}$ & $0(0,0)$ & 0.03 & $0(0,1.5)$ & $0(0,2.5)$ & 0.65 \\
\hline
\end{tabular}

*Placebo nebulized saline increased cough, and was therefore removed from the randomization in phase II.

ues because the majority of patients have the same outcome; accordingly, only non-zero values of outcomes were compared when assessing inter-rater reliability. Inter-rater reliability of ordinal observations was assessed using the kappa statistic, while continuous variables were assessed using the two-way mixed intraclass correlation coefficient.

\section{Results}

In phase I, 74 patients were enrolled out of 92 patients approached (79\% consent rate) between December 1996 and June 1997. Departures from protocol were narcotic administration $(n=7)$ or intraoperative administration of drugs with airway effects $(n=9)$. Results are presented on 58 patients in phase I. Procedures performed in phase I were insertion of myringotomy tubes $(21 \%)$, ophthalmologic surgery $(21 \%)$, hernia surgery $(19 \%)$, other urologic $(25 \%)$, and other $(12 \%)$. There were no demographic differences between groups (Table I). The nebulized saline group had an increased incidence of cough during emergence.

In phase II, 62 patients were enrolled out of 90 patients approached $(69 \%$ consent rate, $P=0.13 \mathrm{FE} v s$ phase I) between November 1997 and June 1998. Departures from protocol were narcotic $(n=6)$, lidocaine $(n=2)$, rectal methohexital $(n=2)$ and propofol $(n=1)$ administration. Results are presented on 51 patients for phase II. Procedures performed were insertion of myringotomy tubes (18\%), hernia surgery (17\%), other urologic (42\%), and other $(24 \%)$.

A recent URI (within the preceding six weeks) was present in 76 patients $(70 \%)$ and an active URI (peak symptoms within seven days) was present in 21 patients (19\%). Analyzing the entire study population, there was no association between either recent URI or active URI and desaturation, cough, stridor, laryngospasm or wheeze (all $P>0.05$ ).
Administration of bronchodilators did not affect any outcome when compared to placebo or non-intervention (Table II). Utilizing an alpha of 0.05 and power of $80 \%$, analysis of these results indicates that 90 patients per group would be needed to demonstrate a difference between groups in stridor-laryngospasm, 440 patients per group for desaturations, and 9,500 patients per group for laryngospasm.

Stridor and laryngospasm tended to occur during emergence - 19 incidents of any degree during emergence $v s$ nine during induction $(P=0.067 \mathrm{FE})$. Stridor accompanied by desaturation $<93 \%$ occurred in eight instances during emergence $v$ s one during induction $(P=$ $0.035 \mathrm{FE}$ ). There was only one instance of laryngospasm severe enough to require muscle relaxant, occurring after removal of a blood-stained laryngeal mask.

Smoke exposure was not correlated significantly with any study outcome. There was no significant difference in outcomes when attendings ps non-attendings managed the anesthetic. The attending anesthesiologist's prediction had no correlation with desaturation $(P=$ $0.41 \mathrm{WRS})$ or laryngospasm $(P=1 \mathrm{FE})$. Wheezing was auscultated in only three patients in the entire study and did not have significant correlation with any of this study's potential outcome predictors.

The data in Table III support a lower adverse event rate for patients managed by mask $v s$ either laryngeal mask airway (LMA) or endotracheal tube. This does not appear to be attributable to a preference for intubating children with recent URI (possibly at risk of adverse events), since the proportion of children with recent URI is similar for those managed by mask vs tube (Table III). Among those patients with instrumented airways (subdividing the right-hand column of Table III), again demographics were similar and intubation was associated with significantly longer desaturations $<95 \%$ than with the LMA (Table IV). 
TABLE III Outcomes by type of airway management, all patients

\begin{tabular}{|c|c|c|c|}
\hline & $\begin{array}{l}\text { Mask } \\
(n=59)\end{array}$ & $\begin{array}{l}\text { LMA or ETT } \\
(n=47)\end{array}$ & $P$ value \\
\hline Age (months) & $28(16,60)$ & $36(13,71)$ & 0.99 \\
\hline Weight $(\mathrm{kg})$ & $13(10,17)$ & $14(10,19)$ & 0.56 \\
\hline Active URI & $11(19 \%)$ & $10(21 \%)$ & 0.81 \\
\hline Time since URI (weeks) & $3(1.3,4)$ & $2.3(0.9,4)$ & 0.53 \\
\hline \multicolumn{4}{|l|}{ Emergence saturations } \\
\hline$<95 \%$, duration $(\mathrm{sec})$ & $0(0,7)$ & $12(0,114)$ & 0.003 \\
\hline \multicolumn{4}{|l|}{ Emergence saturations } \\
\hline$<85 \%$, duration $(\mathrm{sec})$ & $0(0,0)$ & $0(0,0)$ & $0.006^{*}$ \\
\hline \multicolumn{4}{|l|}{ Any emergence saturation } \\
\hline$<85 \%$ & $0(0 \%)$ & $8(25 \%)$ & 0.039 \\
\hline Stridor-laryngospasm & $6(30 \%)$ & $5(18 \%)$ & 0.49 \\
\hline \multicolumn{4}{|l|}{ Laryngospasm with } \\
\hline desaturation & $4(20 \%)$ & $2(7 \%)$ & 0.22 \\
\hline Wheeze & $0(0 \%)$ & $5(11 \%)$ & 0.017 \\
\hline
\end{tabular}

*Interpretation $=$ though the median, 25th percentile and 75 th percentile are all zero, the upper quartile of patients differed substantially, as shown in the next row. LMA = laryngeal mask airway; $\mathrm{ETT}=$ endotracheal tube; active URI = less than one week since peak symptoms; time since URI $=$ number of weeks since peak URI symptoms.

TABLE IV Outcomes by type of airway management, instrumented airways only

\begin{tabular}{|c|c|c|c|}
\hline & $\begin{array}{l}L M A \\
(n=20)\end{array}$ & $\begin{array}{l}\text { ETT } \\
(n=27)\end{array}$ & P value \\
\hline Age (months) & $41(23,72)$ & $19(9,63)$ & 0.12 \\
\hline Weight (kg) & $16(11,24)$ & $13(9,18)$ & 0.14 \\
\hline Active URI & $5(25 \%)$ & $5(19 \%)$ & 1 \\
\hline Time since URI (weeks) & $2(0.8,3.3)$ & $2.8(0.9-4)$ & 0.60 \\
\hline Emergence saturations & & & \\
\hline $\begin{array}{l}<95 \% \text {, duration }(\mathrm{sec}) \\
\text { Emergence saturations }\end{array}$ & $0(0,12)$ & $52(0,170)$ & 0.014 \\
\hline$<85 \%$, duration $(\mathrm{sec})$ & $0(0,0)$ & $0(0,0)$ & 0.44 \\
\hline Stridor-laryngospasm & $6(30 \%)$ & $5(18 \%)$ & 0.49 \\
\hline $\begin{array}{l}\text { Laryngospasm with } \\
\text { desaturation }\end{array}$ & $4(20 \%)$ & $2(7 \%)$ & 0.22 \\
\hline Wheeze & $4(22 \%)$ & $1(4 \%)$ & 0.069 \\
\hline
\end{tabular}

LMA = laryngeal mask airway; ETT = endotracheal tube; active $\mathrm{URI}=$ less than one week since peak symptoms; time since URI = number of weeks since peak URI symptoms.

In 44 cases, a second blinded and independent observer recorded end-points simultaneously with a high inter-rater reliability of end-points (Table V).

Mean values for both the peak expiratory value of the second derivative of the capnograph with respect to time and the area under the curve (the predictors) were derived from an average of $9^{6,14}$ breaths for each patient. These predictors derived from capnography were not correlated with history of URI, did not
TABLE V Inter-rater reliability of outcome observations

\begin{tabular}{lll}
\hline & Observations* $^{*}$ & Reliability \\
\hline $\begin{array}{l}\text { Cough } \\
\begin{array}{l}\text { Minor desaturations } \\
<95 \%(\mathrm{sec})\end{array}\end{array}$ & 14 & $0.93(0.81,0.93)$ ICC (95\% CI) \\
$\begin{array}{l}\text { Major desaturations } \\
<85 \%(\mathrm{sec})\end{array}$ & 7 & $0.94(0.86,0.97)$ ICC $(95 \% \mathrm{CI})$ \\
Laryngospasm score & 14 & $0.96(0.78,0.99)$ ICC (95\% CI) \\
\hline
\end{tabular}

ICC $=$ intra-class correlation. ${ }^{*}$ Cases in which two observers were present, in which at least one observed a non-zero outcome.

change with administration of the study drugs, and were not associated with the outcomes of either laryngospasm or desaturation (all $P>0.10$ ).

\section{Discussion}

We found that the administration of either an anticholinergic or a beta-agonist bronchodilator did not produce an outcome difference in this highly selected population. The size of study required to show an outcome difference (according to power analysis) suggests that any beneficial effect of bronchodilators is clinically trivial.

Neither the attending anesthesiologist, nor preoperative capnography were able to predict the occurrence of adverse events. While adverse events did occur, the desaturations were brief even in the absence of supplemental oxygen, and only one patient required a muscle relaxant for laryngospasm.

Previous studies have shown an association between an active URI on the day of surgery as reported by the parents and clinical adverse outcomes, ${ }^{8,26,27}$ but no association between the presence of a URI by objective criteria ${ }^{19}$ and these outcomes.

Endotracheal intubation was associated with emergence desaturation, as seen in a large retrospective study. ${ }^{2}$ The use of a LMA gave rise to less adverse events than endotracheal intubation. However, such a question was better addressed by a prospective study that randomized patients to LMA $p s$ intubation, ${ }^{28}$ which showed less respiratory events and wheezing with the LMA.

There are several possible explanations for the lack of bronchodilator effect in this study: 1) the beneficial effect of the bronchodilator may be lost among the multitude of other factors contributing to emergence adverse events; 2) bronchoconstriction may not be a factor in emergence adverse events, since wheezing was rarely observed; 3 ) if the cholinergic receptor is indeed damaged by a virus, as seen in the animal 
model, ${ }^{29}$ an anticholinergic drug may not be able to exert its effect on a damaged receptor; 4) the study drug may not have been delivered adequately to its target. However, this seems unlikely given that this method of drug administration is effective in childhood asthma. ${ }^{30}$

Capnography failed to show any association with outcome. Although capnography has been shown to correlate with airway resistance in adults making a forced vital capacity exhalation, ${ }^{17}$ our data quality was poor in keeping with children's inability to cooperate with testing. The limitations of the capnography recordings are the unavoidable leak around the facemask with the first technique, and aspiration of room air with the second technique used. It is conceivable that recording and plotting $\mathrm{CO}_{2}$ vs expired volume ${ }^{31}$ (rather than time) might have produced better correlations with outcomes, but obtaining accurate exhaled volumes in awake children is difficult.

Our reported rate of laryngospasm is higher than that reported by others. ${ }^{3,7,8,32,33}$ We employed a broader definition of stridor-laryngospasm and used a blinded observer to assess stridor-laryngospasm, rather than relying on the anesthesiologist's report. Self-reported rates of laryngospasm may be low since physicians may subconsciously deny that their patients are having a complication. ${ }^{34}$ We chose to measure duration of desaturation, rather than its mere incidence as in previous studies, to better depict the spectrum of adverse events in this setting.

There are several limitations in this study. We excluded patients having airway surgery, despite knowledge that this is a risk factor for laryngospasm. ${ }^{8}$ We wished to avoid the confounding influence of surgical factors (blood in the airway) upon end-points. This study represents a population in which bronchodilator therapy may have a low yield, and thus, may have masked any beneficial effects of the drugs. Accordingly, the results of this study should not be applied to the common pediatric operation of tonsillectomy without further data. The results evince an apparent lack of utility of bronchodilators in the population studied. The study bears repeating in patients at higher risk for complications before dismissing the role of preoperative bronchodilator therapy in this setting.

We did not standardize airway management or anesthetic technique, in order to maximize enrollment of patients. Future studies could examine a subset of this population at higher risk for emergence complications having a standardized anesthetic and consistent airway management. Our desire to have a broad spectrum of pediatric anesthetics, and hence more generalizable results, has led to many confounding factors that may have masked a beneficial effect. Yet, this reflects clinical practice more closely.

Paired observers had remarkably consistent observations as assessed by the intra-class correlation coefficient. The use of a blinded observer to record emergence adverse events may be useful in future studies in this area, as a more objective means than relying on complications as reported by the anesthesiologist.

We did not track patients whose surgery was cancelled prior to the day of operation - knowledge of their eventual outcomes would provide a more complete picture of the effects of URI on the complications studied.

Cancellation of elective surgery because of a recent URI is troublesome for patients, families, ${ }^{11}$ and operating room staff. Cancellation is often advocated based on the association between URI and adverse events, but such events were not predictable from preoperative data in these patients. The adverse event rate in this study is low, suggesting that clinicians can safely proceed with surgery despite URI in a selected population. To be clear, that population is defined by the study methods as afebrile ASA I-II patients with no lung disease or lung findings, having elective non-cavitary, non-airway surgery less than three hours in length. Further research is needed to define children with URI symptoms who are at low risk for perioperative respiratory complications.

\section{References}

1 Olsson GL. Bronchospasm during anaesthesia. A computer-aided incidence study of 136929 patients. Acta Anaesthesiol Scand 1987; 31: 244-52.

2 Cohen MM, Cameron CB. Should you cancel the operation when a child has an upper respiratory tract infection? Anesth Analg 1991; 72: 282-8.

3 Tait AR, Knight PR. Intraoperative respiratory complications in patients with upper respiratory tract infections. Can J Anaesth 1987; 34: 300-3.

4 McGill WA, Coveler LA, Epstein BS. Subacute upper respiratory infection in small children. Anesth Analg 1979; 58: 331-3.

5 DeSoto H, Patel RI, Soliman IE, Hannallah RS. Changes in oxygen saturation following general anesthesia in children with upper respiratory infection signs and symptoms undergoing otolaryngological procedures. Anesthesiology 1988; 68: 276-9.

6 Levy L, Pandit UA, Randel GI, Lewis IH, Tait AR. Upper respiratory tract infections and general anaesthesia in children. Peri-operative complications and oxygen saturation. Anaesthesia 1992; 47: 678-82.

7 Rolf N, Cote CJ. Frequency and severity of desaturation events during general anesthesia in children with 
and without upper respiratory infections. J Clin Anesth 1992; 4: 200-3.

8 Schreiner MS, O'Hara I, Markakis DA, Politis GD. Do children who experience laryngospasm have an increased risk of upper respiratory tract infection? Anesthesiology 1996; 85: 475-80.

9 Kinouchi K, Tanigami H, Tashiro C, Nishimura M, Fukumitsu K, Takauchi $\Upsilon$. Duration of apnea in anesthetized infants and children required for desaturation of hemoglobin to $95 \%$. The influence of upper respiratory infection. Anesthesiology 1992; 77: 1105-7.

10 Tait AR, Reynolds PI, Gutstein HB. Factors that influence an anesthesiologist's decision to cancel elective surgery for the child with an upper respiratory tract infection. J Clin Anesth 1995; 7: 491-9.

11 Tait AR, Voepel-Lewis T, Munro HM, Gutstein HB, Reynolds PI. Cancellation of pediatric outpatient surgery: economic and emotional implications for patients and their families. J Clin Anesth 1997; 9: 213-9.

12 Monto AS, Ullman BM. Acute respiratory illness in an American community. The Tecumseh study. JAMA 1974; 227: 164-9.

13 Empey DW, Laitinen LA, Jacobs L, Gold WM, Nadel $J A$. Mechanisms of bronchial hyperreactivity in normal subjects after upper respiratory tract infection. Am Rev Respir Dis 1976; 113: 131-9.

14 Picken JJ, Niewoehner DE, Chester EH. Prolonged effects of viral infections of the upper respiratory tract upon small airways. Am J Med 1972; 52: 738-46.

15 Kil HK, Rooke GA, Ryan-Dykes MA, Bishop MJ. Effect of prophylactic bronchodilator treatment on lung resistance after tracheal intubation. Anesthesiology 1994; 81: 43-8.

16 Olsson GL, Hallen B. Laryngospasm during anaesthesia. A computer-aided incidence study in 136929 patients. Acta Anaesthesiol Scand 1984; 28: 567-75.

17 You B, Peslin R, Duvivier C, Vu VD, Grilliat JP. Expiratory capnography in asthma: evaluation of various shape indices. Eur Respir J 1994; 7: 318-23.

18 Teculescu D, Aubry C, Chau N, Locuty J, Pham QT, Manciaux $M$. Respiratory symptoms or signs on the day of the study alter pulmonary function in teenagers. Int J Epidemiol 1988; 17: 209-16.

19 Tait AR, Knight PR. The effects of general anesthesia on upper respiratory tract infections in children. Anesthesiology 1987; 67: 930-5.

20 Chan CS, Brown IG, Kelly CA, Dent AG, Zimmerman $P V$. Bronchodilator responses to nebulised ipratropium and salbutamol singly and in combination in chronic bronchitis. Br J Clin Pharmacol 1984; 17: 103-5.

21 Okanlami OA, Fryer AD, Hirshman C. Interaction of nondepolarizing muscle relaxants with $\mathrm{M}_{2}$ and $\mathrm{M}_{3}$ muscarinic receptors in guinea pig lung and heart. Anesthesiology 1996; 84: 155-61.

22 Hutton N, Wilson MH, Mellits ED, et al. Effectiveness of an antihistamine-decongestant combination for young children with the common cold: a randomized, controlled clinical trial. J Pediatr 1991; 118: 125-30.

23 Lewis RA, Lewis MN, Tattersfield AE. Asthma induced by suggestion: is it due to airway cooling? Am Rev Respir Dis 1984; 129: 691-5.

24 Schoeffel RE, Anderson SD, Altounyan RE. Bronchial hyperreactivity in response to inhalation of ultrasonically nebulised solutions of distilled water and saline. $\mathrm{Br}$ Med J (Clin Res Ed) 1981; 283: 1285-7.

25 van Noord JA, Smeets JJ, Maesen FP. A comparison of the onset of action of salbutamol and formoterol in reversing methacholine-induced bronchoconstriction. Respir Med 1998; 92: 1346-51.

26 Parnis SJ, Barker DS, Van Der Walt JH. Clinical predictors of anaesthetic complications in children with respiratory tract infections. Paediatr Anaesth 2001; 11: 29-40.

27 Tait AR, Malviya S, Voepel-Lewis T, Munro HM, Siewert $M$, Pandit $U A$. Risk factors for perioperative adverse respiratory events in children with upper respiratory tract infections. Anesthesiology 2001; 95: 299-306.

28 Tait AR, Pandit UA, Voepel-Lewis T, Munro HM, Malviya $S$. Use of the laryngeal mask airway in children with upper respiratory tract infections: a comparison with endotracheal intubation. Anesth Analg 1998; 86: 706-11.

29 Fryer AD, Jacoby DB. Parainfluenza virus infection damages inhibitory $\mathrm{M}_{2}$ muscarinic receptors on pulmonary parasympathetic nerves in the guinea-pig. Br J Pharmacol 1991; 102: 267-71.

30 Schuh S, Parkin P, Rajan A, et al. High- versus lowdose, frequently administered, nebulized albuterol in children with severe, acute asthma. Pediatrics 1989; 83: 513-8.

31 Ream RS, Schreiner MS, Neff JD, et al. Volumetric capnography in children. Influence of growth on the alveolar plateau slope. Anesthesiology 1995; 82: 64-73.

32 Roy WL, Lerman J. Laryngospasm in paediatric anaesthesia. Can J Anaesth 1988; 35: 93-8.

33 Chripko D, Bevan JC, Archer DP, Bherer N. Decreases in arterial oxygen saturation in paediatric outpatients during transfer to the postanaesthetic recovery room. Can J Anaesth 1989; 36: 128-32.

34 Mizrahi T. Managing medical mistakes: ideology, insularity and accountability among internists-in-training. Soc Sci Med 1984; 19: 135-46. 